\title{
RHEUMATIC PERICARDITIS IN CHILDHOOD
}

\author{
BY \\ LEONARD FINDLAY, M.D., D.Sc., JAMES W. MACFARLANE, M.B., Ch.B., \\ and MARY M. STEVEnSON, M.A., M.D. \\ (From the Department of Pædiatrics, Glasgow University, and the Royal \\ Hospital for Sick Children, Glasgow.)
}

Our work on rheumatism has necessitated a careful scrutiny of the case histories of all examples of the disease which have come under our observation. During the course of this survey there have emerged several facts in its life history which seem worthy of record, since they appear to be somewhat at variance with current teaching. Of these perhaps the most striking is the almost invariable association of pericarditis with arthritis, and, in contrast to what is generally believed, the slight degree of correlation between it and chorea.

Since much of the argument in the present communication is based on clinical experience a crucial question is the ability to diagnose the condition of pericarditis during life and to say with any degree of certainty whether it is or is not present. All clinicians will agree that in its milder forms it is most elusive. This is especially true during infancy when pericarditis, commonly, however, of a purulent nature, is usually only discovered at autopsy. Some writers, however, have stated that when rheumatism attacks the heart the whole organ (endocardium, myocardium and pericardium) is involved. As Sturges ${ }^{1}$ has said, 'the rheumatic heart inflammation of children when pericardial is always endocardial as well, and when endocardial is extremely likely, with the recurrence of rheumatism, to involve the pericardium also.' This may be true if the statement is confined to the recurrence of rheumatism, but it is surprising to us to learn that Sturges noted that 'out of 100 fatal cases of heart disease occurring at the Children's Hospital, Great Ormond street, between June, 1881, and April, 1892, of which 54 were of rheumatic origin and 46 due to other causes, in 6 only was there no evidence of pericarditis.' Roberts, who quoted the above, remarks that his experience is in complete accord with that of Sturges, and Cheadle" states that "pericarditis is almost always found post mortem in the fatal heart disease of children.' Should such a state of matters really be the case then it would appear futile to discuss the question of pericarditis apart from carditis and to attempt to express in figures the relative frequency with which pericarditis is associated with one or other manifestation of rheumatism. That it is true, however, we very much doubt, even although it bears the impress of authorities like Sturges and Cheadle. 
At the Royal Hospital for Sick Children, Glasgow, we have records of 30 post-mortem examinations in children dying from all forms of rheumatic heart disease, and only in 15 , i.e., 50 per cent., was there implication of the pericardium. If the cases in which pericarditis was discovered before death are excluded, we are left with 19 cases, and in only 4 of these was involvement of the pericardium an accidental finding. In one of these four cases the pericardium was densely adherent from mischief occurring apparently two years previously, and in the other three the inflammation of the pericardium was very early and of moderate degree. Thus our experience is at variance with that of Roberts, Sturges and Cheadle and in our opinion justifies from clinical evidence the consideration of the relationship of pericarditis to other rheumatic phenomena.

We have records of 51 examples of rheumatic pericarditis admitted to the Royal Hospital for Sick Children, Glasgow, between 1915 and 1928 inclusive. The sequence of events in all the cases reviewed is given in Table 1, and summaries of the clinical histories of those patients in whom chorea occurred are given in the appendix.

A. Cases in which the heart alone was involved. In 4 of the cases (No. 2, 36,45 and 51 ) the cardiac condition was the only manifestation of the mischief but that this was of a rheumatic nature we have no doubt. In one (No. 2) there occurred at the age of 7 years and 10 months a typical attack of pericarditis from which the boy recovered, though he has been left with some enlargement of the heart, a loud and definite musical mitral systolic murmur and dyspnœa on exertion. Another of the patients (No. 45) was a girl who had had a cardiac murmur since an attack of scarlet fever at 2 years : she came under our observation at the age of 5 years with typical pericardial effusion during the course of which a crop of subcutaneous nodules appeared on the elbows, knuckles, knees and ankles. This girl died from a failing heart at the age of 7 years, when an adherent pericardium and botton-hole mitral orifice were discovered at the autopsy. Another of these patients (No. 36) was a girl who came under observation at the age of 9 years with a history that at the age of 7 years she had been attacked with vomiting, cardialgia and orthopnœa, when the doctor diagnosed a 'very bad heart.' There had never been any complaint of pain in the joints or of tonsillitis, and none of the relatives had ever suffered from rheumatism. After this illness, which lasted for threemonths, the girl had remained fairly well till one week previously, when she developed a headache, was sick and vomited, and had a return of the præcordial pain and dyspnœa. On admission there was slight fever, the heart was very much enlarged, and a loud systolic murmur was audible at the mitral area and well conducted to the axilla. The child's condition rapidly deteriorated and she died two weeks after admission to hospital. At the autopsy were found a densely and diffusely adherent pericardium, and enlargement of the heart; and fresh minute vegetations were discovered on both the aortic and the mitral valves. The fourth purely cardiac example (No. 5l) of rheumatism in this series was a boy of $5 \frac{1}{2}$ years. This child had been taken ill three weeks before coming under observation with severe pain over the heart and the right side of 
abdomen, and was admitted to a surgical ward as a case of appendicitis. No operation was performed and all pain having disappeared after a week's residence the child was dismissed; but the first night he was home the pain returned, and continuing to be severe, he was readmitted, but to a medical ward. There was only slight fever $\left(101^{\circ} \mathrm{F}\right.$.), the pulse numbered 130 , the heart was much enlarged, and all over the præcordia, but loudest at the apex and well conducted to the left, a loud systolic murmur was audible. The child died after 20 days, and during the last week of his illness fever, which had disappeared on the day after admission, returned. At autopsy the pericardial sac was found to contain an excessive amount of a slightly turbid fluid, and both visceral and parietal layers of the pericardium were injected. The heart was enlarged and fresh typical rheumatic vegetations were found on the cusps of the mitral valve. In this case also no history of any other rheumatic manifestation, either in the child himself or in his relatives, could be obtained.

B. Cases with pericarditis as the sole cardiac lesion. In 2 of the cases (No. 22 and 30) pericarditis apparently was the sole cardiac lesion. At least no cardiac murmur suggesting endocardial disease, either at the time of the acute cardiac illness or subsequently, could be made out. As both of these patients recovered this limitation of the rheumatic mischief to the pericardium must remain problematical. Both children had suffered from arthritis, and in neither was there a history of chorea.

C. Cases with arthritis and pericarditis. -44 of the 51 patients had suffered at some time or other from arthritis. In 17 the arthritis preceded by a definite period the appearance of pericarditis. In 26 patients the pericarditis ensued during the attack of arthritis, on 14 occasions during the first attack, on 10 during a second attack and on 2 occasions during a third attack. In 1 of the cases (No. 37) the pericarditis occurred prior to the other manifestations (chorea, arthritis and endocarditis,) of rheumatism.

D. Cases with chorea and pericarditis. -15 of the patients had suffered from chorea, but 13 of them had also had arthritis, so that in only 2 children was chorea the sole other rheumatic manifestation than the cardiac involvement. One of these children (No. 47) had suffered from chorea with endocarditis 2 years prior to the attack of pericarditis; while in the case of the other (No. 27), in which the history left something to be desired, pericarditis and endocarditis immediately preceded the onset of chorea. Both of these children died from the illness of which the pericarditis was a manifestation, so that it is possible that if they had survived, arthritis might have ensued at a later date. In 6 of the choreic cases, including the one mentioned above, the attack of chorea had occurred a considerable time before the development of pericarditis ; in 2 of the cases the attack of chorea occurred after the onset of pericarditis ; in 5 the pericarditis developed while the chorea was present, but in three of them there was also arthritis at the same time. Thus in only 2 of the cases did chorea and pericarditis occur simultaneously when there could be any question of considering one a complication of the other.

Chorea and arthritis occurring simultaneously.-At this point it is appro. priate to make some mention of the simultaneous occurrence of arthritis and 
TABLE I

Showing SEquence of events In CASES OF PERICARditis.

(In this table A signifies arthritis; G.P. growing pains; C chorea ; E endocarditis; $\mathbf{P}$ pericarditis and $\mathrm{N}$ nodules. When the manifestations occurred synchronously the symbols are united by a + sign.)

\begin{tabular}{|c|c|c|c|c|c|c|c|c|c|c|}
\hline \multirow{2}{*}{$\begin{array}{c}\text { Case } \\
\text { No. }\end{array}$} & \multirow[t]{2}{*}{ Sex } & \multirow{2}{*}{$\begin{array}{l}\text { Age at onset } \\
\text { of pericarditis } \\
\text { in years }\end{array}$} & \multicolumn{7}{|c|}{ Rheumatic Attacks } & \multirow{2}{*}{ Result } \\
\hline & & & lst & 2nd & 3rd & 4 th & 5 th & 6 th & 7th & \\
\hline 1 & M. & 11 & G.P. & $\mathbf{A}+\mathbf{E}+\mathbf{P}$ & & & & & & \\
\hline 2 & M. & $77_{1}^{10}$ & $\mathbf{P}+\mathbf{E}$ & & & & & & & \\
\hline 3 & M. & 13 & $A+E$ & $\mathbf{P}$ & & & & & & \\
\hline 4 & M. & $6 \frac{1}{4}$ & $\mathbf{A}+\mathbf{P}+\mathbf{E}$ & & & & & & & \\
\hline 5 & M. & $10 \frac{1}{3}$ & $\mathbf{A}+\mathbf{E}+\mathbf{P}$ & & & & & & & Died \\
\hline 6 & M. & 11 & $\mathrm{~A}+\mathrm{E}$ & $\mathbf{P}$ & & & & & & Died \\
\hline 7 & M. & 10 & A & A & $\mathrm{A}+\mathrm{E}+\mathbf{P}+\mathrm{N}^{*}$ & & & & & \\
\hline 8 & M. & 5 & A & $\mathbf{E}$ & & & & & & Died \\
\hline 9 & M. & $8 \frac{1}{2}$ & A & $\mathrm{A}$ & $\mathbf{A}+\mathbf{E}+\mathbf{P}$ & $A^{*}$ & & & & \\
\hline 10 & M. & 9 & A & $\mathbf{E}+\mathbf{P}$ & & & & & & \\
\hline 11 & M. & 5 & A & $A+E+P$ & & & & & & \\
\hline 12 & M. & $11 \frac{1}{2}$ & $\mathbf{A}+\mathbf{P}+\mathbf{E}+\mathbf{N}$ & A & & & & & & Died $\dagger$ \\
\hline 13 & M. & 7 & $\mathbf{A}+\mathbf{E}$ & $\mathbf{P}$ & & & & & & Died \\
\hline 14 & F. & 6 & $\mathrm{C}+\mathbf{E}$ & A & $\mathbf{P}$ & & & & & \\
\hline 15 & F. & 9 & $\mathrm{~A}+\mathrm{P}+\mathrm{E}$ & & & & & & & \\
\hline 16 & F. & $7 \frac{1}{4}$ & $\mathrm{~A}+\mathrm{E}$ & $\mathbf{P}$ & & & & & & Died \\
\hline 17 & F. & $7 \frac{1}{2}$ & $\mathbf{A}+\mathbf{E}+\mathbf{P}+\mathbf{N}$ & & & & & & & Died \\
\hline 18 & F. & 12 & $\mathrm{C}$ & $\mathbf{A}+\mathbf{P}+\mathbf{E}$ & & & & & & Died \\
\hline 19 & F. & 8 & $\mathrm{~A}+\mathrm{P}+\mathrm{E}$ & & & & & & & Died \\
\hline 20 & F. & $11 \frac{1}{2}$ & A & $\mathrm{C}+\mathrm{E}$ & $\mathbf{A}+\mathbf{P}$ & & & & & Died \\
\hline 21 & F. & 7 & $\mathrm{~A}+\mathrm{E}$ & $\mathrm{C}$ & $\mathbf{P}$ & & & & & \\
\hline 22 & F. & 9 & $\mathbf{A}+\mathbf{P}$ & & & & & & & \\
\hline 23 & F. & $6 \frac{1}{2}$ & $\mathrm{~A}+\mathrm{E}+\mathrm{C}+\mathrm{P}$ & & & & & & & \\
\hline 24 & M & $7 \frac{2}{3}$ & $A+E+P$ & & & & & & & Died \\
\hline 25 & F. & 12 & G.P. & $\mathbf{C}+\mathbf{E}+\mathbf{P}$ & $C+P$ & & & & & Died \\
\hline 26 & F. & 10 & $\mathbf{C}+\mathbf{A}+\mathbf{E}+\mathbf{P}$ & & & & & & & Died \\
\hline 27 & F. & 5 & $\mathbf{P}+\mathbf{E}+\mathbf{C}$ & & & & & & & Died \\
\hline 28 & F. & 9 & $\mathrm{~A}+\mathrm{E}$ & $\mathrm{P}$ & & & & & & Died \\
\hline 29 & F. & 9 & $\mathrm{~A}+\mathrm{P}+\mathrm{E}$ & A & & & & & & \\
\hline 30 & F. & 11 & & $\mathrm{~A}+\mathrm{P}$ & & & & & & \\
\hline 31 & F. & $13 \frac{1}{2}$ & $\mathrm{~A}+\mathrm{P}+\mathrm{E}$ & & & & & & & \\
\hline 32 & F. & 11 & $\mathbf{A}+\mathbf{E}+\mathbf{P}$ & & & & & & & \\
\hline 33 & F. & 7 & A & $\mathrm{A}+\mathrm{E}+\mathrm{P}$ & & & & & & \\
\hline 34 & F. & $10 \frac{1}{2}$ & A & $\mathrm{P}+\mathbf{E}$ & & & & & & Died \\
\hline 35 & M. & 6 & $A+E$ & $\mathbf{A}+\mathbf{P}$ & & & & & & Died \\
\hline 36 & F. & 7 & $\mathbf{P}$ & $\mathbf{E}$ & & & & & & Died \\
\hline 37 & M. & 5 & $\mathbf{P}$ & $\mathrm{C}+\mathrm{A}+\mathrm{E}$ & & & & & & Died \\
\hline 38 & F. & $81:$ & A & $\mathrm{E}+\mathrm{P}$ & & & & & & \\
\hline 39 & F. & $11 \frac{3}{4}$ & $\mathbf{A}+\mathbf{E}$ & $\mathbf{P}$ & & & & & & \\
\hline 40 & $\mathbf{F}$ & 9 & A & $\mathbf{A}+\mathbf{P}+\mathbf{E}$ & & & & & & \\
\hline 41 & F. & $10 \frac{1}{2}$ & A & $\mathrm{C}+\mathrm{E}+\mathrm{P}$ & & & & & & Died \\
\hline 42 & F. & 11 & $\mathrm{~A}+\mathrm{C}+\mathrm{E}$ & $\mathbf{A}+\mathbf{P}$ & & & & & & Died \\
\hline 43 & F. & 8 & $\mathrm{C}$ & A & $C+E$ & $\mathrm{C}$ & $\mathbf{P}$ & & & Died \\
\hline 44 & F. & 7 & $\mathbf{A}+\mathbf{E}$ & $\mathbf{A}+\mathbf{P}$ & & & & & & \\
\hline 45 & F. & 5 & $\mathrm{E}$ & $\mathbf{P}+\mathbf{N}$ & & & & & & Died \\
\hline 46 & M. & $6 \frac{1}{2}$ & C & $\mathrm{C}+\mathrm{E}$ & $\mathrm{C}$ & $\mathrm{C}+\mathrm{A}+\mathrm{P}+\mathrm{N}$ & & & & \\
\hline 47 & F. & $11 \frac{2}{12}$ & $C+\mathbf{E}$ & $\mathrm{P}$ & & & & & & Died \\
\hline 48 & F. & 10 & $A+E+N$ & $A+N$ & $\mathrm{P}+\mathrm{N}$ & & & & & \\
\hline 49 & F. & 11 & $\mathrm{C}$ & $\mathrm{C}+? \mathrm{E}$ & A & $\mathrm{C}+\mathrm{E}$ & $\mathrm{C}$ & A & $\mathbf{P}$ & \\
\hline 50 & M. & 5 & A & $\mathrm{A}+\mathrm{E}+\mathrm{P}$ & & & & & & Died \\
\hline 51 & M. & $5 \frac{1}{2}$ & $\mathbf{E}+\mathbf{P}$ & & & & & & & Died \\
\hline
\end{tabular}

*The fact that in these cases the endocarditis is associated with thethird rheumatic attack would seem opposed to what we have already written, viz. :- that heart in our experience is usually affected during first two rheumatic attacks. We only obtained a history of the first two attacks in these cases and did not observe the children till during the third attack when the heart was already found affected. 
chorea. Though a history of chorea and arthritis occurring simultaneously is often obtained from the parents, it is in our experience one of the rarest phenomena. In fact, in only 5 of the 51 children who suffered from pericarditis did chorea and arthritis occur anything like synchronously. This does not of course mean that we have not more frequently observed these two manifestations follow closely on one another. An acute painful arthritis has never been observed along with an active chorea while the cases have been under observation in hospital, unless in hemichorea when the muscular contractions and the arthritis were on opposite sides of the body. We haveseen the onefollow immediately on the heels of the other, with perhaps the swelling of the joints persisting after the appearance of chorea, but by which time all pain and tender. ness had disappeared. We have also observed alternation of the two-chorea subsiding, to be replaced by arthritis, and after its disappearance chorea returning. One can imagine the excruciating suffering which the child would endure did chorea and arthritis occur together. We have seen sedatives administered for the control of the movements, but never because they seemed to be causing the child any special pain.

The alternation of chorea and arthritis has been noted by most authors and even the early writers, e.g., Copland ${ }^{3}$, Bright ${ }^{4}$, Begbie ${ }^{5}$ and Churchill ${ }^{6}$ call attention to it; but never does one find a mention of them occurring together. In fact Roger ${ }^{9}$, and still later Radcliff" 5 , said they were antagonistic, a dictum which was reiterated a few years ago by Pfaundler ${ }^{7}$. Lepehne ${ }^{8}$, who took Pfaundler to task for making such a statement was, however, only able to unearth two recorded examples of this phenomenon after a thorough search of the literature. Both cases emanated from Senator's clinic and in one of them Lepehne states that the chorea caused such acute pain that morphia had to be administered for its relief. These two cases on account of their extreme rarity rather throw into relief, than detract from, the general truth of Roger's axiom. We know the tendency in rheumatic arthritis for the mischief truly to flit from joint to joint, and Goodhart and Still ${ }^{10}$ have remarked that when endocarditis or pericarditis develops it is usual for chorea if present to disappear, so that by analogy alone one would not expect chorea and arthritis to occur simultaneously.

Sex incidence of pericarditis.-Of our cases of pericarditis 32 were females and 19 males, which is a proportion somewhat different from that usually recorded. Still ${ }^{11}$ for instance states that of 53 examples of pericarditis observed by him 32 were boys and 20 girls ; and he contrasts, as most authors do, the sex incidence of this manifestation with that of chorea. We find, however, that Sibson ${ }^{12}$ notes that of his cases of rheumatic pericarditis under 20 years of age males and females were equally affected (17 of each) whereas of the 29 patients over 20 years of age 18 were males and 11 females. Church ${ }^{13}$ also states that he did not find in his experience the reputed great preponderance of males, and Cheadle ${ }^{2}$ in his classical article in Allbutt's System of Medicine does not touch at all on the sex incidence of pericarditis. Most authors, however, agree with Still, and the different sex incidence of pericarditis and chorea 
was indeed used as an argument in the early days to contravert the theory that pericarditis was the cause of chorea.

In our experience the sex incidence of chorea and pericarditis is the same, though, as we have shown above, it is comparatively rare to have the two diseases in the one individual. So far as the sex incidence of chorea is concerned our experience coincides with that of other authors (Table 2).

TABLE 2

SEX INCIDENCE OF CHOREA

\begin{tabular}{|c|c|c|c|c|c|c|c|}
\hline & & & & & Males & Females & Total. \\
\hline R.H.S.C., (dlasgow & . & $\ldots$ & . & $\cdots$ & $27 \cdot 5 \%$ & $72 \cdot 4 \%$ & 276 \\
\hline Still ${ }^{14}$, London. & . & . & . & . & $28.0 \%$ & $72 \cdot 0 \%$ & 150 \\
\hline Bendix ${ }^{15}$, Berlin. & . & . & . & .. & $26.0 \%$ & $74.0 \%$ & 一 \\
\hline Kerley ${ }^{16}$, New York. & & $\cdots$ & . & $\ldots$ & $40.0 \%$ & $60 \cdot 0 \%$ & - \\
\hline
\end{tabular}

Age incidence of pericarditis. - The earliest age at which we diagnosed the condition was five years but, as in one of these cases (No. 37) the pericardial sac was found at post-mortem examination obliterated by dense fibrous adhesions, the mischief must have commenced at a much earlier date. It was impossible from the history to hazard an opinion regarding the date of onset of the pericarditis. As seen from the age distribution of the cases coming under our observation given in Table 3, it would seem to be relatively more frequent in the earlier years of childhood.

TABLE 3

Age distribution of cases of pericarditis.

\begin{tabular}{|c|c|c|c|c|c|c|c|c|c|c|}
\hline Age in years & . & $\tilde{5}$ & 6 & 7 & 8 & 9 & 10 & 11 & 12 & 13 \\
\hline \multirow[t]{2}{*}{ No. of cases } & . & 7 & 5 & 9 & 4 & 6 & 6 & 10 & 2 & 2 \\
\hline & & & $r_{21}$ & & & 16 & ـ & 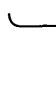 & $\gamma_{14}$ & \\
\hline
\end{tabular}

It is unsafe, however, to draw any definite conclusion from this material as in a children's hospital the younger children form a much greater proportion of the patients. The exprrience of Sibson ${ }^{12}$ lends some support to our figures sinca he writes that though he observed more cases of rheumatism after 20 years of age than before 20 years of age, a larger proportion of the latter developed pericarditis, in fact 25 per cent. of the latter as against 16 per cent. of the former.

Association of nodules and pericarditis.-In 6 of the examples of pericarditis (Nos. 7, 12, 17, 45, 46 and 48) subcutaneous rheumatic nodules were present, 
but in all there was clinical or pathological evidence of endocarditis as wellIn one of the cases (No. 48) nodules appeared with each bout of the disease.

Fate of patients with pericarditis. - Of the 51 cases 26 died, 24 during the acute phase of the disease and 2 at a later date from cardiac decompensation. The gravity of pericarditis during childhood is remarked upon by Still ${ }^{11}$ who holds that both the immediate and the remote prognosis are serious. He states that he has hardly ever seen a case, even if it recovered from the acute illness, who did not present symptoms of cardiac disability. Gairdner ${ }^{28}$, on the other hand, says that he has never seen a patient die from rheumatic pericarditis, but then he is referring chiefly to adults and not to children.

The present condition so far as is known of the 25 cases in our series who have survived is as follows, and fully corroborates Still's contention. In 1 case there are neither signs or symptoms of cardiac disease (the child was last seen in the spring of 1928); in 7 cases there are signs of cardiac disease but no symptoms ; in 9 there are definite symptoms of cardiac disability as well as signs, and in 3 the disability is extreme. 5 of the children could not be traced.

\section{Historical survey of association of pericarditis and chorea.}

All present-day authors admit that pericarditis in rheumatism is most often associated with arthritis, but they also hold that not infrequently it is dependent on chorea. Cowan's' ${ }^{17}$ statement that 'chorea is responsible for many cases of pericarditis' may be taken as typical of present-day opinion as expressed in our text-books. It is, however, difficult to understand on what grounds such a conclusion has been arrived at, since almost without exception the illustrative examples of pericarditis in the text of the various memoirs (Watson ${ }^{18}$, Babington ${ }^{19}$, Bright ${ }^{4}$, Henoch ${ }^{2}$, Ashby and Wright ${ }^{21}$ ) on the subject have, just as in our own series of cases, been associated with arthritis and not with chorea. This modern view, at least in its implication, is in marked contrast to that held by the earlier writers who believed that pericarditis was the cause of chorea.

The history of the association of chorea and pericarditis is an interesting one and reveals in a striking fashion the human failing to associate as necessarily cause and effect any two conditions which may occur simultaneously. Copland ${ }^{22}$ receives the credit of having for the first time observed pericarditis and chorea in the one individual. In 1821 he recorded the case of a boy of 9 years who developed arthritis followed by chorea, and made a good recovery from both. Six months later cardialgia, generalized pains and anasarca appeared, and he again got well. Ten months still later chorea and arthritis returned : on this occasion the chorea was very severe and ultimately led to a generalized flaccid paresis and death. The boy, however, retained consciousness till the end and there was no nuchal rigidity : in fact, special mention is made of the flaccidity of the muscles of the neck, both of which are points of importance in view of the post-mortem findings. At the autopsy meningitis, pericarditis and ascites were discovered. As above mentioned 
this is considered by most writers on the subject the first recorded example of the association of chorea and pericarditis, but in view of the meningitis discovered post-mortem. we at the present day cannot agree that the fatal illness at least was rheumatic in nature. The association of septicæmia with arthritis, pericarditis and nervous phenomena, and its confusion withrheumatism was a frequent error in pre-bacteriology days, and even yet is one which in the absence of a complete bacteriological examination of the joint effusion and cerebro-spinal fluid, or a post-mortem examination, is apt to arise. Curiously, Latham, who wrote his monumental work on Diseases of the Heart in 1820, i.e., one year before the publication of Copland's article, makes no mention during his very exhaustive consideration of pericarditis of any association of it with chorea.

In those early days the cause of chorea was somewhat of an enigma, but with the growth of rational medicine it became less and less the custom to incriminate a lesion which was not visible. In virtue of the presence of choreiform movements in gross cerebral lesions (both cerebral and meningeal) the current belief at that time was that inflammation of the coverings of the spinal cord was the causal factor. In 1839, however, Richard Bright ${ }^{4}$ read a paper to the Medico-Chirurgical Society of London on spasmodic disease accompanying disease of the pericardium. Bright did not doubt that inflammation of the membranes of the spine could cause a chorea, but he did not think this essential as he no doubt had observed cases going to post-mortem examination in which it was absent. In this communication he recalled the above-mentioned case of Copland and recorded several observations of his own. In not all, however, can one be sure from the facts supplied that pericarditis existed, but in two there appears little room for doubt. Though the pericarditis did develop during the course of the chorea, it is interesting in view of our findings to note that in both instances there had been antecedent typical rheumatic arthritis. One of the cases was a boy of 17 years who had had arthritis which was soon followed by chorea, and in whom Bright suspected pericarditis which was verified at the autopsy. The other patient was a young woman who also had had arthritis followed by chorea, during the course of which pericardial friction appeared : this patient made a complete recovery.

As there was no evidence of any gross nervous lesion in the case submitted to post-mortem examination, Bright held that disease of the nervous system itself was not necessary, and suggested that irritation of the pericardium might be the ætiological factor, this being transmitted to the brain by the phrenic nerves ' whose terminations would be embedded in the seat of the inflammation.' He summed up his argument in these words :-

I doubt not that in some cases the coverings of the cerebro-spinal mass may be, and are, implicated, yet I believe that the much more frequent cause of chorea, in conjunction with rheumatism, is the inflammation of the pericardium and that the irritation is communicated thence, probably, to the spine, just as the irritation of other parts, as of the bowels, the gums, or the uterus is communicated and produces the same diseases : for I do not at all incline to the belief, that inflammation, in or about the spine, is necessary to induce chorea.

Bright's theory of the cause of chorea was supported by Babington.19 who in an article shortly afterwards (1841) recorded a series of examples of 
chorea which had come under his observation. He corroborated Bright's statement that chorea was not always dependent on disease of the spinal cord, and thought that the irritation might be transmitted from a distance, as in the case of disease of the heart and pericardium 'through the irritation of the plexus and ganglia which so entirely surround that organ' just as 'irregular menstruation may produce a like effect through the lumbar plexus.' In a foot-note to this article Babington mentioned that Addison had told him that he had seen a very large number of cases of chorea and only two had been without a decided mitral or left ventricular bruit: 'in these two, however, there was disease of the heart and in one case, examined after death, there was found old thickening of mitral valve and very recent pericarditis.' Babington continued - Should further investigation prove chorea to be more immediately dependent on disease of the heart than has hitherto been suspected the merit of the discovery will certainly be due to Dr. Addison.' Of the 25 cases which Babington recorded not all would nowadays be considered examples of Sydenham's chorea. Nine, however, are typical of the condition. In three there occurred pericarditis, and in the only one in which there is no mention of arthritis he stated that the history of the illness was unsatisfactory. Arthritis occurred prior to the pericarditis in both of the other two cases; in one of them the chorea developed subsequent to the appearance of the pericarditis, and in the other the chorea and pericarditis occurred synchronously.

It was left to Begbie (1847), however, to put the relationship between chorea and pericarditis in proper perspective. Begbie ${ }^{5}$ was a firm believer in the rheumatic nature of chorea, and discussed the matter at great length in a communication which he read to the Medico-Chirurgical Society of Edinburgh in 1847. He showed from his own clinical experience and that of his colleagues that chorea and rheumatism may 'occur conjointly or severally in different individuals of the same family.' He described one family in which the father had rheumatic fever, and at the same time his eldest child, a girl of 5 years, was suffering from a severe attack of chorea. Later the father again had rheumatic fever and the girl, without any subsequent chorea or arthritis, developed an advancing endocarditis of the mitral valve from which she died. In another family of 9 children, a girl of $12 \frac{1}{2}$ years had chorea, a younger sister also at $12 \frac{1}{2}$ years developed chorea; later on a brother at the age of 18 suffered from rheumatic fever with pericarditis ; and still later the younger girl had an attack of typical rheumatic fever followed by endocarditis, and during convalescence a second seizure of chorea. In the third family, in which the mother had had acute rheumatism after her first delivery, a boy of 13 had chorea supervening on a second attack of arthritis; an elder brother, after several attacks of rheumatic fever and one of chorea, developed aortic endocarditis ; and a sister at the age of $\mathbf{1 7}$ years had chorea. From these family histories the conviction of the identity of the rheumatic nature of chorea, arthritis and carditis was forced on Begbie and he wrote ;-

I cannot help coming to the conclusion that the simple and true view of their relation is to be found in the morbid condition of the blood which is admitted to exist in the rheumatic constitution; and this explanation will apply equally to chorea occurring in individuals or 
families inheriting the rheumatic diathesis-to chorea occurring in connection with rheumatism but without cardiac complication-and to chorea associated with pericarditis or endocarditis or both; the inflammatory affection of the fibrous tissues, as well as the spasmodic affection of the muscles, and the derangement of the nervous system, originating in the same specific disorder of the circulating fluids.

His prophesy that 'the labours of the microscope and the progress of organic chemistry, may ere long reveal to us in what this disorder consists' has unfortunately, however, not been fulfilled even now almost 100 years later.

One would have thought that a clinician of Graves's acumen would have had something to say on this matter, but in his famous Lectures on Clinical Medicine published one year after Begbie's communication there is not a single reference to any association between chorea and pericarditis. It is questionable, however, if Graves had any idea of the relationship between chorea and rheumatism, although he was quite definite concerning the part played by the latter infection in pericarditis. Nevertheless the teaching that chorea was rheumatic in nature thereafter gradually became accepted (Sée, Roger, Trous$\left.\operatorname{seau}^{23}\right)$. Chief interest, however, veered off from its association with pericarditis and became centred round the search for an explanation of the nature of the disturbance of the brain. Begbie gave no theory, probably because being a true scientist he saw no reason to justify him in suggesting any. The meningeal cause was discarded and the pericarditic origin of the irritation seemed too fantastic, as well as not being an invariable or even frequent accompaniment. Kirkes $^{24}$, who was quite decided that chorea was a rheumatic manifestation, pointed out that "it allies itself with endocardial and not pericardial disease, and that whenever chorea occurred in connection with rheumatism the valves of the left chamber of the heart were inflamed, and therefore that the association is not between chorea and rheumatism but really between chorea and valvular disease of the heart.' From this association he developed the thesis that chorea was due to embolism of the very minute arteries in the brain, the source of the emboli being the vegetations on the valves. This explanation was adopted by Hughlings Jackson ${ }^{26}$ who even specified the site of the embolism as the corpus striatum. The fact pointed out by Vogel ${ }^{27}$, that while rheumatic carditis was more frequent in boys chorea vas more frequent in girls, did not shake belief in this theory which held sway for many a day. Apparently in consequence of this new conception of the causation of chorea all interest in its association with pericarditis lapsed, and subsequent writers as Trousseau, Gairdner ${ }^{28}$ and Radcliffe make no mention of it. In fact, Sir Thomas Watson" ${ }^{29}$ in his exhaustive lecture on pericarditis cetailed at great length the nervous phenomena (convulsions, delirium and coma) which may accompany it, but made no single mention of chorea.

It would appear to be Sir William Osler ${ }^{30}$ who resuscitated interest in our time in the association of pericarditis and chorea, since it is in his writings that one again first meets a reference to it. In his monograph on chorea published in 1895, pericarditis in chorea received individual consideration. He also recalled the work of Copland and Bright, and stated that ' in 19 of the 73 recent autopsies in chorea which I have collected' (we suppose he means from 
the literature though he does not say so) 'pericarditis occurred as a complication, and in 17 it was associated with endocarditis. In 8 of the cases there was a history of acute rheumatism (arthritis). One case had subacute rheumatism, one rheumatic pains, while nine had not had acute arthritis.' The example of associated pericarditis and chorea which Osler quoted is not only not a striking one, but occurred in the practice of his colleague Sinkler who published it. The patient was a boy of 6 years who had arthritis in February, 1888, chorea in March, 1888,-- the chorea continued for months-and an attack of typical pericarditis with effusion in January, 1889, by which time, however, the chorea had disappeared. Thus just as in the cases described by the earlier writers arthritis was again a precursor. This is also true of practically all recent writers. They all speak of chorea as being responsible for pericarditis, but all the illustrative cases of rheumatic pericarditis which they quote had all suffered from arthritis as well as chorea ${ }^{31}$. The only exception that we have come across is Nobécourt ${ }^{31}$, who recorded two instances of pericarditis and chorea as the only manifestations of rheumatism. The one was a personal observation in a boy of 7 years who for 12 days had 'some pericardial rubs' in addition to a well marked mitral systolic murmur. The other instance he quoted from Cadet and Gassicourt affecting a boy of 9 years in whom a well marked pericarditis with effusion occurred during a second attack of chorea, and in whose case there is no mention of him having suffered from arthritis. From our own cases (see appendix), and also from those of other writers quoted above, the very varying sequence in which the various rheumatic manifestations appear is so striking that one does not hesitate to believe that not only in the two cases recorded by us, if they had survived, but also if the subsequent history of the cases quoted by Nobécourt were known, an attack of arthritis would fall to be recorded.

Nobécourt in his treatment of the question remarked on the difference in the picture of pericarditis as observed in arthritis and in chorea. He said that pericarditis in association with chorea is occult and does not reveal itself by symptoms or signs except occasional friction rubs at the base of the heart. The examples, however, which have come under our observation, details of which are supplied in the appendix, do not support any such conclusion. In all of the 15 cases in which the pericarditis was present during the course of chorea the cardiac condition was severe, and death resulted in 10 .

\section{Conclusion.}

It would thus seem that although pericarditis may very occasionally occur as the sole manifestation of rheumatism, or during the course of an attack of chorea, or even, but still more rarely, in an individual who has never had any other rheumatic manifestation than chorea, the association of pericarditis and chorea is anything but close, and, so far as rheumatism is concerned, arthritis is the almost invariable precursor or accompaniment of pericarditis. It was Kirkes who said that chorea and endocarditis, and not chorea and pericarditis, are allied; and we would say it is arthritis and pericarditis which are 
related. The fact that they are both examples of inflammation of a serous sac would make it exceedingly likely that there would be this relationship, but the immunity of the pleura, the peritoneum, and the pia-arachnoid to the rheumatic infection prevents us from pushing this analogy too far.

But in our opinions, to speak of either arthritis or chorea being responsible for pericarditis engenders a totally wrong conception of the rheumatic infection, and in relating cause and effect is as untenable as the thesis propounded almost 100 years ago by Bright and Babington that pericarditis caused chorea. Pericarditis just as endocarditis, arthritis and chorea, and also rheumatic nodules, is a manifestation of the rheumatic infection-the one is not dependent on the other but these are the various seats of election for the development of the rheumatic reaction ; and, as we know only too well, they may, especially during childhood, with the possible exception of the nodules, appear in any sequence.

This is an experience which has been familiar to all writers on rheumatism (Copland, Bright, Churchill, Radcliffe). Begbie ${ }^{5}$ saw its significance and in the words previously quoted has put the matter in its proper perspective. Within comparatively recent times Cheadle ${ }^{3}$ in his classical article on rheumatism in childhood again has expressed the same view. Cheadle wrote ' sometimes an arthritis appears first ; in other cases an endocarditis ; now and again a chorea inaugurates the morbid series . . . they may follow any order of sequence'; and further, when speaking of pericarditis, that it 'may arise at any step in the rheumatic series : first or last; alone or combined with any one or more of the other manifestations such as endocarditis, arthritis, the evolution of nodules or chorea.'

\section{REFERENCES.}

1. Sturges, O., quoted by Roberts. Allbutt's Syst. of Med., Lond., 1898, V, 733.

2. Cheadle, W. B., Allbutt's Syst. of Med., Lond., 1898, III, 44.

3. Copland, J., Dict. of Med., Lond., 1844, I, 328.

4. Bright, R., Trans. Med. Chir. Soc. Lond., Lond., 1839, XXII, 1.

4a. Bright, R., Ibid., 15.

5. Begbie, J., Contrib. to Pract. Med., Edin., 1862, 68.

6. Churchill, F., Dis. of Children, Dublin, 1868, 418.

7. Pfaundler, M., Zeit. f. Kinderh., Berlin, 1926, XXX, 397.

8. Lephene, K., Zeit. f. Kinderh., Berlin, 1926, XXX, 394.

9. Roger, quoted by Pfaundler. Ibid.

10. Goodhart, J. F., \& Still, G. F., Dis. of Children, Lond., 1905, 663.

11. Still, G. F., Common Disorders and Dis. of Child., Lond., 1915, 505.

12. Sibson, F., Reynold's Syst. of Med., Lond., 1877, IV, 188.

13. Church, W. S., Allbutt's Syst. of Med., Lond., 1897, III, 15.

14. Still, G. F., Common Disorders and Dis. of Child., Lond., 1915, 514.

15. Bendix, B., Mod. Clin. Med. Padiatrics, N.Y., 1910, 580.

16. Kerley, C. G., Pract. of Pediatrics, Philad., 1924, 750.

17. Cowan, J. M., Dis. of the Heart, Lond., 1914, 389.

18. Watson, T., Lect. on the Prin. and Pract. of Physic., Lond., 1871, I, 667.

19. Babington, B. G., Guy's Hosp. Rep., Lond., 1841, VI, 411.

20. Henoch, E., Dis. of Child. (Syn. Soc. Trans.), Lond., 1888, I, 481, 
21. Ashby, H., \& Wright, G. A., Dis. of Children, Lond., 1899, 520.

22. Copland, J., London Med. Repository, Lond., 1821, XV, 23.

23. Trousseau, A., Clin. Med. (Syd. Soc. Trans.), Lond., 1868, I, 394.

24. Kirkes, quoted by Watson, Ibid., I, 674.

25. Radcliffe, C. B., Reynold's Syst. of Med., Lond., 1872, II, 190.

26. Hughlings Jackson, quoted by Radcliffe, Ibid., 198.

27. Vogel, quoted by Watson, Ibid., I, 677.

28. Gairdner, W. T., Edin. Med. J., Edin., 1860, V, 736.

29. Watson, T., Ibid., II, 322.

30. Osler, W., On Chorea, Lond., 1894, 47.

31. Nobécourt, P., Clin. Med. des Enf., Paris, 1925, 27.

\begin{abstract}
APPENDIX.
No. 13. J.K., male, 5 years. Admitted to hospital 29/12/19. Chorea 8 weeks and arthritis 6 weeks previously. Admitted with chorea. V.S. mitral murmur, nodules on elbows and knees but no evidence of arthritis. 3 weeks after admission, fever and pericardial friction. Died suddenly 3 months after admission. At P.M. examination pericardium obliterated by œdematous fibrous tissue, no free exudate, recent vegetations on mitral valve.
\end{abstract}

No. 27. J.McF., female, 5 years. Came under observation $15 / 2 / 18$ with fever and dyspnœa of 3 weeks' duration. Father had had rheumatic fever 7 years previously. Admitted with fever, dyspnœa, slight chorea of right arm and leg, pericardial effusion and friction, and V.S. mitral murmur. Died suddenly 3 days after admission. At autopsy bread and butter pericardial exudate, and extensive endocarditis of mitral valve.

No. 26. N.C., female, aged 10 years. Admitted to hospital 12/10/20. 3 weeks previously erythema nodosum ; 2 weeks later chorea with pains in ankles and knees which were swollen. On admission temperature $101^{\circ}$, severe generalized chorea, swelling of both knee joints, right tender, heart enlarged with V.S. mitral murmur. Fever continued, cardiac dullness became pyramidal in shape extending as high as second rib with muffling of sounds but no friction. Chorea subsided somewhat, but child got weaker and died suddenly 8 days after admission. At P.M. examination old and recent pericarditis, and endocarditis of aortic and mitral valves.

No. 18. E.McC., female, 12 years. Admitted to hospital 13/7/25. History of chorea for 1 molith, then 2 weeks, later dyspnœa and cardialgia ; 2 days before admission swelling and pain in left ankle joint. On admission temperature $100 \cdot 2^{\circ} \mathrm{F}$., slight chorea of right leg and arm, swelling of left ankle ; child cyanosed, fingers clubbed, great increase in area of cardiac dullness in all directions, loud pericardial friction, V.S. mitral murmur, dullness to percussion and moist. ràles at both bases. Died suddenly 18/7/25. No P.M. examination permitted.

No. 20 E.W., female, $11 \frac{1}{2}$ years. Admitted to hospital 29/11/23. 2 years previously, after a severe wetting, acute rheumatic fever and confined to house for several weeks. Soon after returning to school developed chorea, treated in Glasgow Royal Infirmary for $3 \frac{1}{2}$ weeks and at this time V.D.H. diagnosed. Remained well afterwards without any symptoms of cardiac disability till 1 week before admission, when complained of pain and stiffness of legs and also 
left arm and shoulder. 2 nights before admission epistaxis and vomiting, pains worse and definitely fevered. On admission very ill, no fever, marked cyanosis and orthopnœa, heart dullness increased in all directions, loud widespread pericardial friction, V.S. mitral murmur. Died 2/12/23. P.M. examination refused.

No. 43. J.S., female, first came under observation at the age of 6 years with history of flitting pains in knees and ankle joints of 6 weeks' duration. 5 weeks before admission movements of legs and face, 2 weeks later erythema nodosum over both shins. Pains in legs had persisted. On admission no fever, moderately severe chorea, no tenderness or swelling of joints, heart not enlarged but V.S. murmur audible at apex ; during this period in hospital mitral stenosis and regurgitation diagnosed. Child seen again at age of 8 years with recurrence of chorea and signs of mitral stenosis and regurgitation : remained in hospital 5 weeks by which time chorea had disappeared. 3 months later admitted to East Park Home for Children under the care of Dr. A. Bankier Sloan : 3 months after admission to East Park Home she developed well marked acute pericarditis and died. No P.M. examination performed.

No. 21. E.B., female, came under observation at the age of 7 years on $7 / 11 / 26$ with a history that for a nasal discharge of some corsiderable duration : tonsils and adenoids had been removed 18 months previously. 4 months previously had been in bed for 3 weeks with rheumatic fever and doctor in attendance said that heart was affected. 2 months ago chorea. 5 days before admission sore throat with headache, vomiting and fever followed by dyspnœa 4 days later. On admission fever, $102 \cdot 4^{\circ}$, rapid breathing ( 56 per min.), heart enlarged in all directions, V.S. mitral murmur and loud to-and-fro pericardial friction. Fever subsided within 3 or 4 days, friction disappeared. Child gradually improved and was dismissed with heart enlarged and a loud V.S. mitral murmur.

No. 41. M.McQ., female, admitted to hospital 28/10/27. In early childhood tubercular adenitis. 2 weeks before admission pain and swelling of ankles and knees, and 2 days before admission jerking movements of right arm and face. Admitted at age of $10 \frac{1}{2}$ years with fever (temperature $101.8^{\circ}$ ), slight swelling of left wrist joint, slight chorea of right hand and enlargement of heart with V.S. mitral murmur. Fever and swelling disappeared within 1 week but chorea persisted. Fever returned during 3rd week of residence in hospital, cardiac dullness increased upwards and over the heart, in addition to V.S. murmur, to-and-fro pericardial friction was audible. Fever subsided somewhat in 10 days and friction became less marked, but chorea persisted, and nodules appeared on elbows and knees. She suddenly became seriously ill, was dyspnœic, developed an irritating cough with profuse frothy bright red sputum and died about 6 hours later. No P.M. examination permitted.

No. 23. J.W., female, $6 \frac{1}{2}$ years. Admitted to hospital 19/5/28. Came under observation with history that 2 days previously had become fevered and had developed pain and swelling in left ankle and knee. Admitted with temperature $100 \cdot 4^{\circ}$, pain and swelling of left ankle and knee, erythema marginatum on abdomen and back, very slight chorea, and enlargement of heart with a mitral systolic murmur. 3 days later increase in fever $\left(103^{\circ}\right)$, pain in joints had gone (probably in response to salicylates); cardiac dullness, however, still further increased, especially upwards, and loud pericardial friction was heard in addition to V.S. murmur at apex; very slight chorea. Fever persisted for 3 weeks, pericardial effusion became extreme. On aspiration of pericardium there was obtained a blood-stained fluid the cellular elements of which were, in addition to red cells, entirely polymorphonuclear cells. Pleural effusion developed at end of febrile period and revealed characters of passive exudate. Child gradually improved and was dismissed with heart enlarged and V.S. mitral murmur.

No. 14. L.S., female, first seen at the age of 5 years with history that 4 months previously had had scarlet fever, and that shortly afterwards there had appeared jerky movements of left hand extending later to right; no history of joint pains. Admitted with severe generalized chorea and a V.S. mitral murmur. Treated with antipyrine for 1 week, isolation for $3 \frac{1}{2}$ weeks and then with liq. arsenicalis, min. xv, t.i.d., for 1 week, but chorea persisted. At this period fever developed and 4 days later acute pain in hip appeared. With salicylates pain in hip 
disappeared and finally subsided. Chorea disappeared 2 months after admission to hospital, and child was dismissed after 3 months residerce. Child again came under observation 3 months after dismissal with cardialgia, dyspnœa amounting to orthopnca. Examination revealed enlargement of heart to right and left, with V.S. mitral murmur and pericardial friction, no great effusion.

No. 25. B.McC., female, came under observation at age of 12 years on 24/6/25. History of cccasional growing pains; chorea at 8 years. 2 weeks previous to admission sore throat, in bed for a few days then allowed up, was dyspnœic and ultimately orthopnœic, requiring two pillows, and developed pain in chest and choreiform movements in right arm and leg. On admission temperature $103^{\circ}$, slight chorea in right hand, cyanosed, orthopnœa, cardiac dullness pyramidal in shape extending to clavicle, course pericardial friction, A.S. and V.S. mitral murmurs, dullness at both pulmonary bases with tubular R.M. and ràle. Fever disappeared within 3 days but child's general condition did not improve, ascites and œdema of feet appeared and child died somewhat suddenly 7 days after admission. At P.M. examination old and recent pericarditis, mitral cusps thickened (orifice $1 \cdot 1$ inches), hypostatic pneumonia at both bases, hypostasis of liver, spleen and kidneys.

No. 42. M.McG., female, came under observation at age of 9 years with history that 2 months previously, 6 weeks after scarlet fever, she developed attack of polyarthritis, and that with treatment all pain and swelling of joints disappeared. Two weeks before coming under observation chorea appeared. On admission, severe chorea with paresis of left arm and leg and loud blowing mitral systolic murmur. During her residence at this time she suffered from arthritis and chorea synchronously, but they alternated somewhat in that when the chorea was most severe the arthritis was least painful and vice versa. Her mother and an elder sister had both died of rheumatic cardiac disease. Child again came under observation at the age of $10 \frac{1}{2}$ years on account of increasing dyspnoa on exertion which had troubled her since her dismissal from hospital. The heart at this time was greatly enlarged and there was evidence of mitral and aortic disease. She improved somewhat and was dismissed home, but returned again 2 weeks later. She again improved with residence in hospital but developed chicken-pox and was transferred to an isolation hospital. She was admitted for the last time at the age of $11 \frac{1}{2}$ years with another attack of arthritis, V.D.H. implicating both mitral and aortic orifices and decompensation. After 2 weeks pericarditis ensued as evidenced by loud friction, and child died 1 month after admission. At autopsy old and recent pericarditis, old endocarditis of both mitral and aortic cusps with much puckering, and in addition recent vegetations on the aortic cusps.

No. 47. A.D., female. History of mild attack of chorea at 9 years and heart at this time said to be affected. Came under observation at the age of 11 years and 2 months on account of pain over præcordia and dyspnœa of 10 days' duration. Onset sudden with cougn and feeling cold and vomiting with rapid development of pain over chest and dyspnœa. On admis sion fever (temperature $102 \cdot 7^{\circ}$ ). Evidence of pericarditis in pyramidal-shaped dullness and loud friction : endocarditis with A.S. and V.S. murmurs and pleural effusion at left base and hæmorrhagic nephritis (blood and casts in urine). Left pleura explored and clear serous fluid withdrawn revealing polymorphonuclear cells and pneumococci. Pericardium explored but only blood obtained Child died 3 weeks after admission. No P.M. examination was permitted.

No. 49. E.T., female, first seen at age of 6 years with typical chorea; heart not affected. Her maternal aunt had chorea during childhood and has V.D.H. At 8 years child had another attack of chorea and was again in hospital : heart still free. At age of 9 years an attack of subacute rheumatic fever followed by another spell of chorea for which admission to hospital was again necessary, and at this time mitral disease diagnosed. When $10 \frac{1}{2}$ years old fourth attack of chorea, by which time mitral stenosis and regurgitation were present ; shortly afterwards slight swelling and pain and tenderness of ankles. At 11 years admitted to hospital once more with a story of præcordial pain, dyspnœa and fever of 1 week's duration. On admission temperature $101^{\circ}$, great enlargement of area of præcordial dullness, pericardial friction, A.S. ihrill with A.S. and V.S. mitral murmurs. Shortly after admission pericardium aspirated ; $40 \mathrm{c.cm}$. very 
slightly blood-stained serous fluid withdrawn which on centrifugalising gave a deposit consisting of lymphocytes, polymorphonuclear and endothelial cells; no organisms seen and no growth obtained on culture.

No. 46. G.C., male, had attack of chorea at age of $3 \frac{1}{2}$ years, and again at age of $4 \frac{1}{2}$ years when he was under our observation and at this time mitral disease was diagnosed. At the age of $6 \frac{1}{2}$ years he had his third attack of chorea with at the same time pains in all his joints and over the heart. On admission to hospital there was fever $101^{\circ}$, moderately severe chorea, nodules on elbows and malleoli and spinous processes of vertebral column; enlargement of area of cardiac dullness with mitral systolic murmur and pericardial friction, moderate effusion. Child gradually improved, nodules disappeared as also did pericardial friction. 